\title{
WCRP COordinated Regional Downscaling EXperiment (CORDEX): a diagnostic MIP for CMIP6
}

\author{
William J. Gutowski Jr. ${ }^{1}$, Filippo Giorgi ${ }^{2}$, Bertrand Timbal ${ }^{3}$, Anne Frigon ${ }^{4}$, Daniela Jacob ${ }^{5}$, Hyun-Suk Kang ${ }^{6}$, \\ Krishnan Raghavan ${ }^{7}$, Boram Lee $^{8}$, Christopher Lennard $^{9}$, Grigory Nikulin ${ }^{10}$, Eleanor O'Rourke ${ }^{10, a}$, Michel Rixen ${ }^{8}$, \\ Silvina Solman ${ }^{11}$, Tannecia Stephenson ${ }^{12}$, and Fredolin Tangang ${ }^{13}$ \\ ${ }^{1}$ Department of Geological and Atmospheric Sciences, Iowa State University, Ames, 50310, USA \\ ${ }^{2}$ Earth System Physics Section, The Abdus Salam International Centre for Theoretical Physics, Trieste, Italy \\ ${ }^{3}$ Australian Bureau of Meteorology, Centre for Australian Weather and Climate Research, Melbourne, Australia \\ ${ }^{4}$ OURANOS, Quebec, Canada \\ ${ }^{5}$ Climate Service Centre, Hamburg, Germany \\ ${ }^{6}$ NIMR, Korea Meteorological Administration, Jeju, Republic of Korea \\ ${ }^{7}$ Indian Institute of Tropical Meteorology, Pune, India \\ ${ }^{8}$ WCRP Joint Planning Staff, World Meteorological Organization, Geneva, Switzerland \\ ${ }^{9}$ University of Cape Town, Cape Town, South Africa \\ ${ }^{10}$ Swedish Meteorological and Hydrological Institute, Norrköping, Sweden \\ ${ }^{11}$ University of Buenos Aires, Buenos Aires, Argentina \\ ${ }^{12}$ Univesity of West Indies, Kingston, Jamaica \\ ${ }^{13}$ The National University of Malaysia, Bangi, Malaysia \\ ${ }^{\mathrm{a}}$ current address: Marine Institute, Rinville, Ireland
}

Correspondence to: William J. Gutowski Jr. (gutowski@iastate.edu)

Received: 13 May 2016 - Published in Geosci. Model Dev. Discuss.: 27 June 2016

Revised: 24 September 2016 - Accepted: 27 September 2016 - Published: 17 November 2016

\begin{abstract}
The COordinated Regional Downscaling EXperiment (CORDEX) is a diagnostic model intercomparison project (MIP) in CMIP6. CORDEX builds on a foundation of previous downscaling intercomparison projects to provide a common framework for downscaling activities around the world. The CORDEX Regional Challenges provide a focus for downscaling research and a basis for making use of CMIP6 global climate model (GCM) output to produce downscaled projected changes in regional climates and assess sources of uncertainties in the projections, all of which can potentially be distilled into climate change information for vulnerability, impacts and adaptation studies. CORDEX Flagship Pilot Studies advance regional downscaling by targeting one or more of the CORDEX Regional Challenges. A CORDEX-CORE framework is planned that will produce a baseline set of homogeneous high-resolution, downscaled projections for regions worldwide. In CMIP6, CORDEX coordinates with ScenarioMIP and is structured to allow
\end{abstract}

cross comparisons with HighResMIP and interaction with the CMIP6 VIACS Advisory Board.

\section{Introduction}

The COordinated Regional Downscaling EXperiment (CORDEX, 2016) was implemented under the auspices of the World Climate Research Program (WCRP) in order to improve downscaling techniques and their use in the provision of robust regional climate information for application in vulnerability, impacts and adaptation (VIA) studies (Giorgi et al., 2009; Jones et al., 2011). Although a number of regional climate model $(\mathrm{RCM})$ and empirical/statistical downscaling (ESD) intercomparison projects have been implemented throughout the years (e.g., Takle et al., 1999; Curry and Lynch, 2002; Fu et al., 2005; Christensen et al., 2007; Mearns et al., 2012; Deque et al., 2012; Solman 
et al., 2013), the lack of common protocols has made it difficult to transfer know-how across these programs. This realization has called for the need to develop a common framework across worldwide regional settings. CORDEX has provided such a framework. The simulation protocol for the first-phase CORDEX activities (hereafter referred to as CORDEX1, Giorgi et al., 2009; Jones et al., 2011) included a validation stream aimed at assessing and improving regional climate downscaling (RCD) models and techniques, along with a regional projection stream aimed at producing large ensembles of projections based on multi-model, multi-RCD approaches. CORDEX1 culminated in a pan-CORDEX conference held in Brussels in November 2013, drawing over 400 abstracts and 500 participants. A number of scientific questions and methodological issues emerged from CORDEX1, which have provided the basis for a revisitation and upgrade of the CORDEX protocol, specifically within the context of the CMIP6 (Climate Model Intercomparison Project 6) framework. In this paper we describe such reflections, with the purpose of providing the background for the development of the next-phase CORDEX activities (hereafter referred to as CORDEX2).

\section{CORDEX goals and emerging scientific challenges from the CORDEX1 activities}

The overall vision of CORDEX is to advance and coordinate the science and application of regional climate downscaling through global partnerships (Giorgi and Gutowski Jr., 2015). Within this vision, CORDEX has a set of four overarching goals:

1. to better understand relevant regional/local climate phenomena, and their variability and changes, through downscaling;

2. to evaluate and improve RCD models and techniques;

3. to produce coordinated sets of regional downscaled projections worldwide; and

4. to foster communication and knowledge exchange with users of regional climate information.

The RCD information samples uncertainties in regional climate change associated with varying forcing from global climate model (GCM) simulations and greenhouse gas (GHG) concentration scenarios, natural climate variability and different downscaling methods (e.g., RCM and ESD). The CORDEX downscaling activities base themselves as much as possible on the latest sets of GCM climate simulations. For example, the CORDEX1 RCM experiments were based on driving GCMs participating in CMIP5, which was an invaluable resource for the design and implementation of CORDEX1 (Jones et al., 2011).

More generally, RCD techniques, including both dynamical and statistical approaches, are being increasingly used to provide higher-resolution climate information than is available directly from contemporary GCMs. The techniques, their applications, and the community using them are broad and varied, and therefore downscaled results must be applied appropriately and the strengths and limitations of different techniques need to be well understood. This requires a better evaluation and quantification of the performance of the different techniques for application to specific problems, along with an understanding of physical processes and uncertainties underlying regional climate projections. Building on experience gained in the global modeling community, a coordinated, international effort to objectively assess and intercompare various RCD techniques provides an optimal means to evaluate their performance, to illustrate benefits and shortcomings of different approaches, and to produce multimodel, multi-method based information, along with associated uncertainty characterization. This should provide a more solid scientific basis for the use of downscaled information in VIA studies and other applications.

To fulfill its vision and address the goals above, CORDEX1 developed a two-stream simulation protocol for a set of 14 continental-scale domains covering essentially all land areas of the globe (CORDEX, 2016). In the first stream (evaluation), the participating RCMs were driven by fields from the ERA-Interim re-analysis of observations (Dee et al., 2011) for the period 1989-2014 and the models were assessed against available observations for the simulation period. In the second stream (projection), the models were run with boundary conditions from GCMs participating in the CMIP5 program (Taylor et al., 2012) for the period 1950 2100 under different greenhouse gas (GHG) emission scenarios. In order to facilitate participation from a broad community, the initial RCM grid spacing was set to $50 \mathrm{~km}$. Priority was given to the Africa domain because of the vulnerability of this continent to climate change and the lack of local infrastructure to carry out regional climate projections. CORDEX1 resulted in the completion of multi-model ensembles for both simulation streams over most of the CORDEX domains, and regional analysis teams were assembled to assess the model simulations (e.g., Endris et al., 2013; Kalognomou et al., 2013; Gbobaniyi et al., 2014). This phase did not initially include ESD because of the lack of coordination across highly varied ESD activities, but an effort is under way to better coordinate and engage ESD in the production of CORDEX-based regional downscaling products and assessments.

An example of simulation results from CORDEX1 appears in Figs. 1 and 2 for precipitation, a challenging field to simulate well. Figure 1 shows seasonal-average bias in precipitation for simulations by an RCM when using reanalysis or GCM boundary conditions. Although there is room for improvement in the simulations, use of GCM boundary conditions in this example does not degrade the simulation compared to using reanalysis boundary conditions: the magnitude and spatial patterns of bias are similar in the two simulations. 


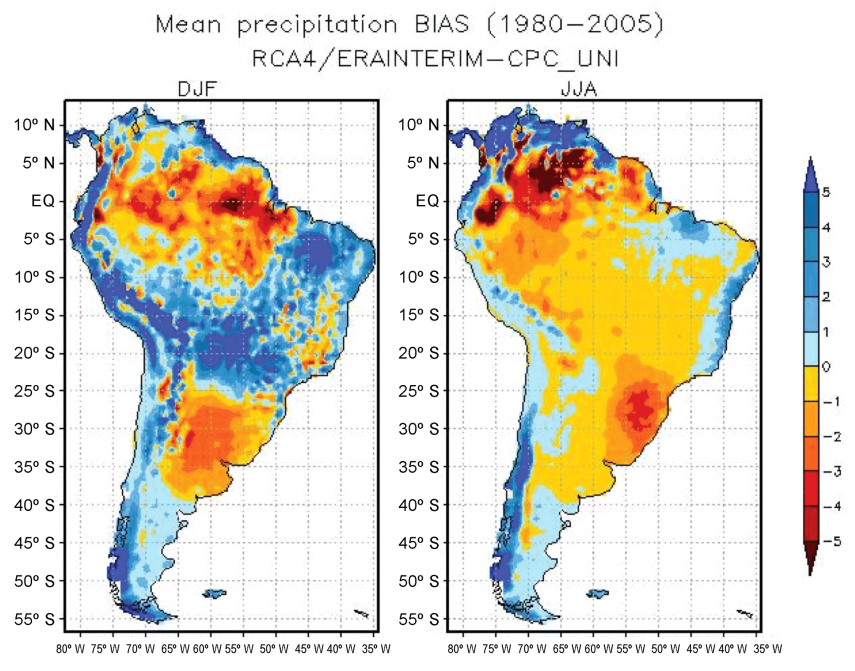

Mean precipitation CHANGE (2071-2100)-(1980-2005) RCP4.5


Figure 1. Bias in 1980-2005 precipitation simulations by regional model RCA4 for South America when using boundary conditions from the ERA-Interim reanalysis (top row) or the EC-Earth GCM run by the Irish Centre for High-End Computing (ICHEC; bottom row). Reference observations are from the CPC Unified GaugeBased Analysis of Global Daily Precipitation (CPC, 2016). Biases are for the seasons December-January-February (DJF; left side) and June-July-August (JJA; right side). Units are $\mathrm{mm} \mathrm{d}^{-1}$.

Figure 2 shows changes in precipitation using the same RCM driven by two GCMs that ran the RCP4.5 projection scenario. The magnitude and spatial pattern of the change is similar in both simulations, suggesting a fairly consistent result, though the bias in contemporary climate simulation (Fig. 1) suggests some caution in accepting the changes without further analysis of underlying changes in precipitation processes.

A number of research issues emerged from the CORDEX1 activities, which were summarized in the CORDEX SAT2 meeting (25-27 February 2015, Norkköping, Sweden) into five CORDEX Regional Challenges and which are currently under discussion by the CORDEX community:

Figure 2. Change in average precipitation for 2017-2100 minus 1980-2005 projected by regional model RCA4 for South America when using the RCP4.5 scenario and two different sources of boundary conditions: the EC-Earth GCM run by the ICHEC (top row) or the low-resolution version of the Max Planck Institute (MPI) earth system model (bottom row). Changes are for the seasons December-January-February (DJF; left side) and June-JulyAugust (JJA; right side). Units are $\mathrm{mm} \mathrm{d}^{-1}$.

1. Added value. The issue of added value of downscaling is often debated, since the use of RCD techniques does not always result in more valuable information for scientific analysis and VIA applications. In addition, downscaling is not intended to correct biases in the large-scale circulations produced by the driving GCMs (an issue traditionally referred to as "garbage in - garbage out"), which substantially influence the performance of RCD techniques. The added value depends on the variable, statistics, and the temporal and spatial scales being considered (e.g., Di Luca et al., 2012; Giorgi and Gutowski, 2015; Torma et al., 2015; Rummukainen, 2016), and whether added value in presentday climate simulation results in more credible finescale climate change signals needs to be assessed ( $\mathrm{Di}$ 
Luca et al., 2013; Giorgi et al., 2016). Therefore, the issue of added value needs to be carefully considered to ensure that there is sufficient improved information gained from the downscaling to justify the resource expenditure for a full downscaling exercise. This issue is particularly relevant in view of the increasing capability of running very high-resolution $(1-5 \mathrm{~km})$, and highly expensive, convection-permitting models for climate applications. Within this context, the value of postprocessing techniques used for VIA application (e.g., bias correction, Berg et al., 2012, or pattern scaling, Tebaldi and Arblaster, 2014) needs to be better explored. ESD methods side-by-side with RCM downscaling can help delineate factors that determine relevant regional patterns or lead to RCD biases.

2. Human element. High-resolution models are especially useful tools to study the effects of human activities on regional and local climates. Typical examples of these effects are those induced by land-use change and urban development (and in particular the growth and spread of coastal megacities) or by aerosols of anthropogenic origin. A number of individual RCM-based studies of land-use and aerosol effects are available in the literature (e.g., Giorgi and Gutowski, 2015); however, a coordinated approach to this issue is required to fully evaluate the importance of local forcings on regional climates.

3. Coordination of regional coupled modeling activities. One of the frontiers in regional climate modeling is the coupling of different climate system components (e.g., atmosphere, ocean, land and ocean biosphere, sea ice, chemistry/aerosol) at the regional scale towards the development of regional earth system models (RESMs). A number of regional coupled modeling activities are currently under way, also within the CORDEX framework (e.g., within the Med-CORDEX, Ruti et al., 2016, or the Arctic-CORDEX, Dethloff et al., 2012); however, these activities would benefit from a greater integration and coordination across regional settings.

4. Precipitation. Precipitation is probably the most important variable for VIA studies, and also one of the most difficult to simulate in current climate models. Changes in precipitation patterns, regimes and extreme events can have severe consequences for a range of society's sectors. In addition, precipitation is a variable where the high resolution of RCMs can provide a substantial added value, in particular concerning the simulation of extremes, mesoscale convective systems and coastal storms (Giorgi and Gutowski, 2015). Uncertainties in projected precipitation changes are large because of model systematic errors and large natural variability, and a characterization of this uncertainty requires the completion of large ensembles. Clearly, CORDEX can provide an optimal framework to improve the robustness in the projection of change in regional hydroclimatic regimes.

5. Local wind systems. Strong regional and local winds, such as the mistral and bora in the Mediterranean, or Chinook winds in western North America, along with intense tropical and extratropical storms, can have devastating impacts, particularly on coastal environments. However, the resolution of current global models is insufficient to accurately simulate local intense wind systems, which are often driven by fine-scale topography or surface-atmosphere exchanges. In addition, there has been comparatively limited analysis of surface winds in both global and regional models. Such analysis would be important for example for economic sectors such as wind energy production. However, inconsistencies can occur between different observation-based wind datasets (Pryor et al., 2009), and observations for wind energy by the private sector are often proprietary and inaccessible to the general public. The CORDEX initiative can provide an essential contribution in this research area.

In addition to the CORDEX Regional Challenges, an important issue is the "distillation" of robust and credible climate information for use in VIA studies. While CORDEX goals include interaction with users of regional climate information, it is not a climate service per se; in this light CORDEX seeks to provide the datasets that are the starting point for distillation, but production of climate information itself requires further effort beyond the remit of CORDEX. Nonetheless, there is often a perception on the user's side that downscaled data is characterized by a high level of credibility. These data, however, are affected by multiple sources of uncertainty (Hewitson et al., 2014a, b): systematic errors in the driving boundary conditions from GCMs and in the RCM and ESD models themselves; natural variability, scenario, and structural uncertainty in the driving GCM climate that propagate into the RCM and ESD models through the boundary forcing; model and technique-dependent response to the same forcing boundary condition fields; internal variability of RCMs; and relative sparseness of the GCM-RCM/ESD simulation matrix. Moreover, natural variability increases at finer spatial scales (e.g., Giorgi, 2001), which enhances the difficulty of identifying forced anthropogenic signals, and observations used to evaluate downscaling can have errors and limitations in their spatial and temporal representativeness. Because of all these sources of uncertainty, care has to be taken to extract the most credible information from RCD ensembles of future climate projections, and this is a little explored area of research in need of much greater attention. This implies, in part, a careful and process-based evaluation of models and understanding of the simulated climate change signals. 
Finally, one of the main problems that emerged from CORDEX1 was the pronounced heterogeneity in terms of availability of simulations across different domains. While for some domains, e.g., Africa, Europe and the Mediterranean, large ensembles of model simulations are available (even at different resolutions), for others, such as central Asia, central America or Australia, only a few experiments have been conducted. This heterogeneity has made it difficult for CORDEX to provide consistent information in international programs such as the Intergovernmental Panel on Climate Change (IPCC) and to transfer across the domains the scientific understanding gained on physical processes and downscaling procedures.

Clearly, addressing the research issues highlighted in this section requires a revisitation of the CORDEX1 framework, leading into a new CORDEX2 phase aimed at providing RCD output, from both empirical/statistical and dynamic downscaling, that can be converted to increasingly useful, consistent and actionable regional to local climate information within the context of the CMIP6 program. Such a revisitation is the subject of the next section.

\section{Plans for the CORDEX2 downscaling and analysis framework}

In the context of CMIP6, CORDEX is a diagnostic model intercomparison project (MIP). The anticipated CORDEX experiments are downscaling activities that will use CMIP DECK, CMIP6 Historical Simulation and ScenarioMIP output to provide input conditions for both statistical and dynamical downscaling under the CORDEX protocol. CORDEX has a core framework of specified regions, resolutions and simulation periods that all regional CORDEX activities adhere to (hereafter referred to as Coordinated Output for Regional Evaluation, or CORDEX-CORE). CORDEXCORE was conceived in part to be responsive to IPCC needs for coordinated simulations that could provide for regions fine-scale climate information beyond that resolved by GCMs. Specific details of downscaling experiments are a function of plans generated by groups participating in each of the CORDEX regions. In particular, for each region a matrix of GCM-RCD experiments is designed based on the need to cover as much as possible different dimensions of the uncertainty space (e.g., different emissions and land-use scenarios, GCMs, RCD models and techniques). Populating this matrix depends on the participation of groups in the different regional domain activities. As a CMIP6-endorsed MIP, all regional downscaling output is expected to be disseminated on the ESGF following the output formatting standard established for CMIP simulations, with output available for unrestricted use as established by CMIP.

An optimal design of GCM-RCD matrices requires the availability of a broad range of driving GCM data (6-hourly meteorological fields, i.e., wind components, temperature, pressure, water vapor), spanning high-end, mid-level and low-end GHG emission/concentration scenarios, and all or at least a large portion of GCMs participating in ScenarioMIP. Ideally, a core set of the GCMs can be used that satisfy the following criteria:

1. cover as well as possible the range of GCM climate model sensitivity;

2. provide acceptable quality of historical climate simulations in the regions where they supply boundary conditions;

3. provide acceptable quality of historical climate simulations for important large-scale features affecting regional climates, such as ENSO and NAO; and

4. have a distinctive model development history.

Such a core set of driving GCMs can allow a program of simulations that efficiently addresses key scientific issues within CORDEX while facilitating comparison and transfer of results and lessons learned across different regions. Projects for individual CORDEX regions may have reasons for choosing additional GCMs, and ultimately, using all GCMs that supply appropriate output for downscaling would be ideal, to make maximum use of the climate information generated by CMIP6 GCMs.

For the CORDEX-CORE framework the focus is on historical climate simulations for the 20th century and projections for the 21 st century, implying that data would be needed minimally for the period 1950-2100 (but ideally 1900-2100). Therefore, as for CMIP5, 6-hourly forcing data from one realization of each contributing GCM are a minimal requirement for dynamical downscaling. Statistical downscaling has more flexibility with input data, but also additional requested GCM output as a consequence of its varied approaches and outputs (see below).

CORDEX activities provide a unique opportunity to deliver a full range of the uncertainties attached with regional climate change projections by creating GCM-RCD matrices. It is therefore important that the uncertainties attached to $21 \mathrm{st}$ century human activities are encapsulated through the availability of multiple scenario simulations. In addition, multiple realizations from some GCMs would allow us to explore another dimension of the uncertainty space, i.e., GCM/RCD internal variability. In order to improve the issue of homogeneity across domains, in the new CORDEX-CORE framework, it is envisioned that a standard core set of RCMs and ESD methods downscale a core set of GCMs over all or at least most CORDEX domains for a minimum set of scenarios (high and low end). This foundational ensemble can be regionally enriched with further contributions (additional GCM-RCD pairs) by individual groups over their selected domains of interest. The RCM model resolution for these core experiments will be in the range of $10-20 \mathrm{~km}$, a resolution that has been shown to provide substantial added value for a variety of climate variables (e.g., Torma et al., 


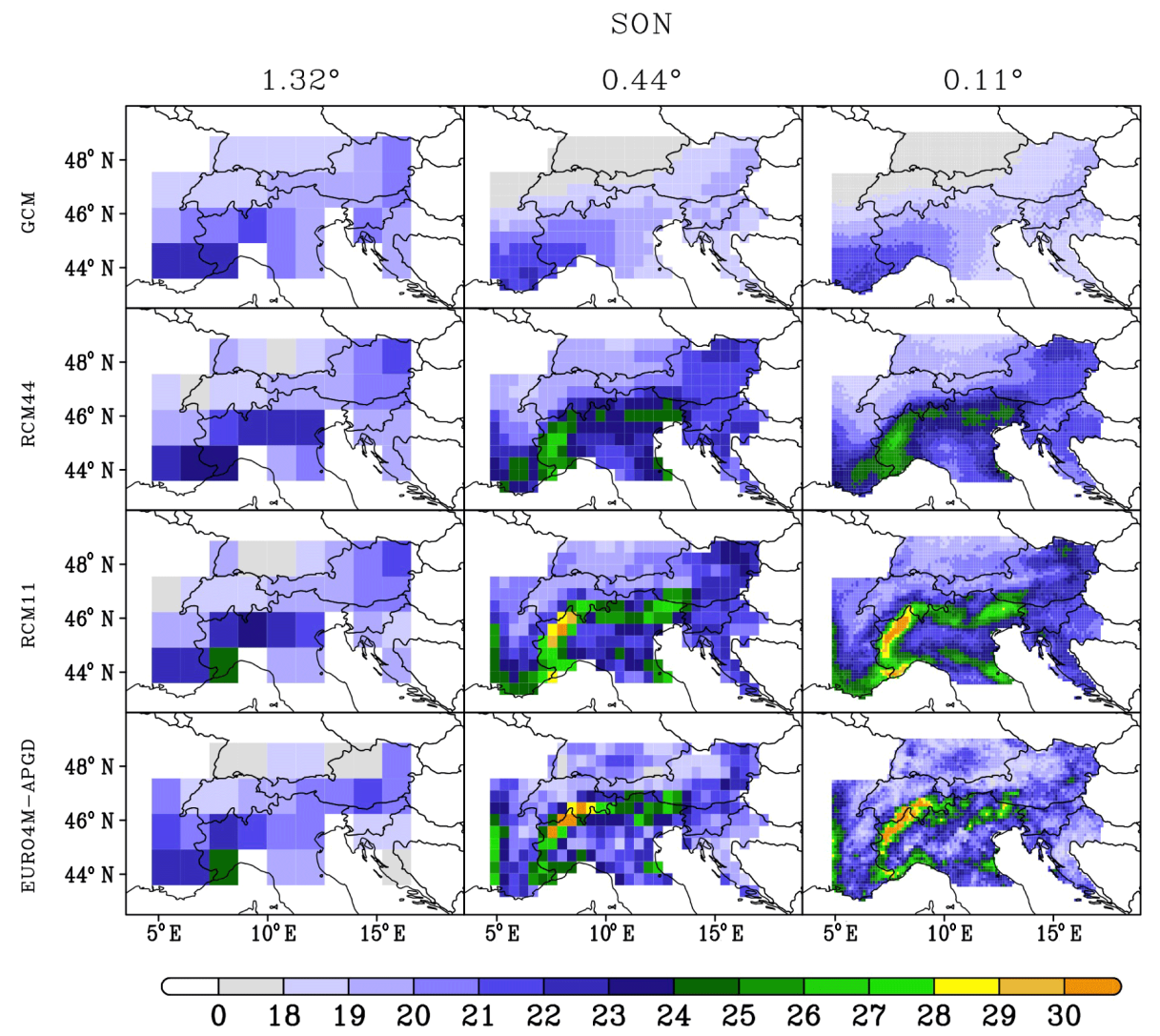

Figure 3. Mean (1976-2005) autumn precipitation (September-October-November, or SON) interpolated to grids at three different resolutions $\left(1.32,0.44,0.11^{\circ}\right)$ for ensembles of driving GCMs, RCMs using $0.44^{\circ}$ resolution, and RCMs using $0.11^{\circ}$ resolution (top three rows, respectively) and the EURO4M-APGD observations. The GCM ensemble consists of four CMIP5 GCMs. The RCM ensembles use five RCMs run at both resolutions under the EURO-CORDEX (Jacob et al., 2013) and Med-CORDEX (Ruti et al., 2016) initiatives and using boundary conditions from one of the four GCMs. Units are $\mathrm{mm} \mathrm{d}^{-1}$. (See Torma et al., 2015, for details.)

2015; Prein et al., 2016; Giorgi et al., 2016) and that represents a significant forward step compared to CORDEX1. ESD methods will also produce gridded output at comparable grid spacing, though one regional enrichment likely will include statistical downscaling directly to observation sites, bypassing issues raised when gridding observations. The resolution envisioned in the CORDEX-CORE will allow direct comparison with the highest-resolution GCM experiments planned for HighResMIP. Figure 3 illustrates the added value that the downscaling to high resolution on the order of $10 \mathrm{~km}$ can provide, especially when compared with observations on relatively fine grids.

In terms of data needs, CORDEX experiments will use output from

1. 30 years of the pre-industrial simulation (CMIP DECK);

2. 1950-2014 from the historical climate simulation (CMIP6 Historical Simulation); and
3. 2015-2100 from the transient scenario climate simulation that uses RCP8.5, 4.5 and 2.6 for one realization of future projection (ScenarioMIP).

Output from these three RCPs will enable us to span the range of plausible climate change, maintain continuity with CMIP5-based downscaling and satisfy needs for climate change information ascertained from user communities, including a scenario (RCP2.6 or new ones if available) close to the 1.5C stabilization target envisioned in the COP21 meeting of December 2015 in Paris. Although one realization is requested, providing output from more realizations and more scenarios (from ScenarioMIP) is welcome to assess the importance of internal model variability.

The downscaling activities will contribute to answering all three of the key questions for CMIP6 through regional simulations with different climate forcings (CMIP Key Question 1), evaluation of physical processes affecting added value and biases in the downscaled results (CMIP Key Question 2) and characterization of the impact of unforced variability, both internally generated and via ensemble boundary conditions, on the ratio of regional climate change signals 
vs. the noise of unforced variability (CMIP Key Question 3). CORDEX will contribute primarily to the WCRP grand challenge on climate extremes and the WCRP effort, in conjunction with other programs, to develop climate information for regions. Some of the downscaling will include evaluation of regional feedbacks associated with land-use change and aerosols, along with regional rendition of GCM responses to different climatic forcings.

Assessments of high-resolution output and added value will seek fine-resolution (10-20 km or less) observational datasets, and in this regard interaction with the Obs4MIPS and Ana4MIPS efforts will be important. Fine-resolution observational datasets are being sought in all CORDEX regions, especially those that could support evaluation of higher-resolution CORDEX runs. In addition, process-based regional analyses will require the acquisition of observations for variables beyond the canonical ones (e.g., temperature and precipitation), such as regional circulations or surface fluxes. Obtaining climatological observations or dataassimilation products at these resolutions is challenging in many parts of the world. CORDEX will help with efforts to make new datasets accessible in standardized formats via the ESGF infrastructure and interface them with regional downscaling output.

\section{Flagship Pilot Studies (FPS)}

The CORDEX-CORE framework based on the use of continental-scale domains will not enable the community to address some of the CORDEX Regional Challenges outlined in Sect. 2, for example the added value of using very highresolution, convection-permitting models or the detailed intercomparison of different downscaling techniques. For this reason, an integral part of CORDEX2 will be the development of so-called Flagship Pilot Studies (FPS). FPS are intended to be targeted studies aimed at addressing specific scientific issues in line with the CORDEX Regional Challenges over selected sub-domains. This will allow groups to run models at a range of spatial resolutions (down to convectionpermitting), to produce large ensembles of RCM simulations and ESD output, and to tailor RCM and ESD experiments towards the study of specific regional processes, feedbacks and circulations. FPS can also provide information leading to illustrative examples of end-to-end activities in which the climate output obtained from large ensembles of models and techniques is distilled into actionable information for targeted VIA applications. A key issue will be the availability of observational datasets of sufficient quality and resolution for an accurate assessment of the model experiments, and in this regard the FPS can provide optimal links between CORDEX and other WCRP core projects (e.g., GEWEX).

The development of FPS is envisioned to be a bottom-up process by which groups of institutes can submit proposals to be reviewed and eventually formally endorsed by the CORDEX Scientific Advisory Team (SAT) through a peer re- view process. A permanent call for proposals with a 4-month deadline cycle is available on the CORDEX website, and the first cycle of proposal submissions is already under way. One advantage of the FPS concept is that a formal CORDEX endorsement might act as an effective leverage for obtaining funding for the selected projects.

\section{Conclusions and outlook}

Since its inception in the late 2000s, the CORDEX initiative has been extremely successful in raising the interest, participation and coordination of a vast and varied climate downscaling community. The number of CORDEX-related peer reviewed publications has grown steadily, along with the participation in CORDEX-related scientific events. The CORDEX1 framework was designed to foster wide participation and to provide the basis for identifying gaps in downscaling research. The CORDEX Regional Challenges and other scientific issues outlined in Sect. 2 have emerged from this process and provide the basis for the development of the CORDEX 2 activities within the CMIP6 context.

CORDEX2 will consist of two main components, the CORDEX-CORE framework, in which a core set of RCMs downscales a core set of GCMs over all or most CORDEX domains at $10-20 \mathrm{~km}$ resolution (with augmentation of the regional ensembles by additional individual groups), and the development of targeted FPS. The CORDEX-CORE addresses the needs for greater homogeneity of multi-model ensemble information across regions and for increased resolution of continental-scale information. Conversely, the FPS aim at more targeted studies addressing specific scientific questions of methodological and regional relevance. Both these components are currently under development and refinement. For example, their structure and specifications were discussed by the broad downscaling community at the third pan-CORDEX conference in Stockholm on 17-20 May 2016 (ICRC-CORDEX, 2016, http://www. icrc-cordex2016.org/index.php), and this discussion is continuing within the different regional communities.

As for CORDEX1, the CORDEX2 activities will also rely on information provided by different CMIP6 projects, most noticeably ScenarioMIP and HighResMIP, and related observational databases such as Obs4MIPs. It is thus important that a communication channel is active across these different programs. Also, the VIA community places great expectations on CORDEX2, so that it is critical for CORDEX to interact with the CMIP6 Vulnerability, Impacts, Adaptation and Climate Services (VIACS) Advisory Board (Ruane et al., 2016) to clearly identify and communicate the value, limitations and uncertainties of the information that can be provided through the CORDEX downscaling experiments. A process-oriented analysis of models and techniques, based on high-quality observational datasets, will thus be a central activity of the CORDEX2 program. 


\section{Data availability}

Data used in the figures are accessible at the Earth System Grid Federation node maintained by the Deutsches Klimarechenzentrum (2016) (https://esgf-data.dkrz.de/projects/ esgf-dkrz/).

Acknowledgements. Preparation of CORDEX engagement in CMIP6 was partially supported by the World Climate Research Programme and the International Project Office for CORDEX at the Swedish Meteorological and Hydrological Institute.

Edited by: A. Colette

Reviewed by: C. M. Goodess and one anonymous referee

\section{References}

Berg, P., Feldmann, H., and Panitz, H.-J.: Bias correction of high resolution regional climate model data, J. Hydrol., 448-449, 8092, 2012.

Christensen, J. H., Carter, T. R., Rummukainen, M., and Amanatidis, G.: Evaluating the performance and utility of regional climate models: The PRUDENCE project, Climatic Change, 81, 16, 2007.

CORDEX: available at: www.cordex.org, last access: 18 September 2016.

CPC: available at: https://climatedataguide.ucar.edu/climate-data/ cpc-unified-gauge-based-analysis-global-daily-precipitation, last access: 18 September 2016.

Curry, J. A. and Lynch, A. H.: Comparing Arctic regional climate models, EOS Trans. AGU, 83, doi:10.1029/2002EO000051, 2002.

Dee, D. P., Uppala, S. M., Simmons, A. J., Berrisford, P., Poli, P., Kobayashi, S., Andrae, U., Balmaseda, M. A., Balsamo, G., Bauer, P., Bechtold, P., Beljaars, A. C. M., van de Berg, L., Bidlot, J., Bormann, N., Delsol, C., Dragani, R., Fuentes, M., Geer, A. J., Haimberger, L., Healy, S. B., Hersbach, H., Hólm, E. V., Isaksen, L., Kållberg, P., Köhler, M., Matricardi, M., McNally, A. P., Monge-Sanz, B. M., Morcrette, J.-J., Park, B.-K., Peubey, C., de Rosnay, P., Tavolato, C., Thépaut, J.-N., and Vitart, F.: The ERA-Interim reanalysis: configuration and performance of the data assimilation system, Q. J. Roy. Meteor. Soc., 137, 553-597, 2011.

Deque, M., Somot, S., Sanchez-Gomez, E., Goddess, C. M., Jacob, D., Lenderink, G., and Christensen, O. B. The spread amongst ENSEMBLES regional scenarios: regional climate models, driving general circulation models and interannual variability, Clim. Dynam., 38, 951-964, 2012.

Dethloff, K., Rinke, A., Lynch, A., Dorn, W., Saha, S., and Handorf, D.: Arctic Regional Climate Models, Arctic Climate Change: The ACSYS Decade and Beyond, Book Series: Atmospheric and Oceanographic Sciences Library, 43, 325-356, doi:10.1007/97894-007-2027-5_8, 2012.

Deutsches Klimarechenzentrum: Earth System Grid Federation node, available at: https://esgf-data.dkrz.de/projects/esgf-dkrz/, last access: 14 November 2016.
Di Luca, A., de Elia, R., and Laprise, R.: Potential for added value in precipitation simulated by high resolution nested regional climate models and observations, Clim. Dynam., 38, 1229-1247, 2012.

Di Luca, A., de Elia, R., and Laprise, R.: Potential for small scale added value of RCM's downscaled climate change signal, Clim. Dynam., 40, 1415-1433, 2013.

Endris, H. S., Omondi, P., Jain, S., Lennard, C., Hewitson, B., Chang'a, L., Awange, J. L., Dosio, A., Ketiem, P., Nikulin, G., Panitz, H. J., Buchner, M., Stordal, F., and Tazalika, L.: Assessment of the performance of CORDEX regional climate models in simulating East African rainfall, J. Climate, 26, 8453-8475, 2013.

Fu, C. B., Wang, S. Y., Xiong, Z., Gutowski, W. J., Lee, D. K., McGregor, J. L., Sato, Y., Kato, H., Kim, J. W., and Suh, M. S.: Regional Climate Model Intercomparison Project for Asia, B. Am. Meteorol. Soc., 86, 257-266, 2005.

Gbobaniyi, E., Sarr, A., Sylla, M. B., Diallo, I., Lennard, C., Dosio, A., Diedhiou, A., Kamga, A., Klutse, N. A. B., Hewitson, B., Nikulin, G., and Lamptey, B.: Climatology, annual cycle and interannual variability of precipitation and temperature in CORDEX simulations over West Africa, Int. J. Climatol., 34, 2241-2257, 2014.

Giorgi, F.: Dependence of surface climate interannual variability on spatial scale, Geophys. Res. Lett., 29, 1101, doi:10.1029/2002GL016175, 2001.

Giorgi, F. and Gutowski Jr., W. J.: Regional Dynamical Downscaling and the CORDEX Initiative, Annu. Rev. Env. Resour., 40, 467-490, doi:10.1146/annurev-environ-102014-021217, 2015.

Giorgi, F., Jones, C., and Asrar, G.: Addressing climate information needs at the regional level: the CORDEX framework, WMO Bulletin, 58, 175-183, 2009.

Giorgi, F., Torma, C., Coppola, E., Ban, N., Schar, C., and Somot, S.: Enhanced summer convective rainfall at Alpine high elevations in response to climate warming, Nat. Geosci., 9, 584-589, 2016.

Hewitson, B. C., Daron, J., Crane, R. G., Zermoglio, M. F., and Jack, C.: Interrogating empirical-statistical downscaling, Climatic Change, 122, 539-554, doi:10.1007/s10584-013-1021-z, 2014a.

Hewitson, B., Janetos, A. C., Carter, T. R., Giorgi, F., Jones, R. G., Kwon, W.-T., Mearns, L. O., Schipper, E. L. F., and van Aalst, M.: Regional context, in: Climate Change 2014: Impacts, Adaptation, and Vulnerability. Part B: Regional Aspects. Contribution of Working Group II to the Fifth Assessment Report of the Intergovernmental Panel on Climate Change, edited by: Barros, V. R., Field, C. B., Dokken, D. J., Mastrandrea, M. D., Mach, K. J., Bilir, T. E., Chatterjee, M., Ebi, K. L., Estrada, Y. O., Genova, R. C., Girma, B., Kissel, E. S., Levy, A. N., MacCracken, S., Mastrandrea, P. R., and White, L. L., Cambridge University Press, Cambridge, United Kingdom and New York, NY, USA, 1133-1197, 2014b.

Jacob, D., Petersen, J., Eggert, B., Alias, A., Christensen, O. B., Bouwer, L. M., Braun, A., Colette, A., Deque, M., Georgievski, G., Georgopoulou, E., Gobiet, A., Menut, L., Nikulin, G., Haensler, A., Hempelmann, N., Jones, C., Keuler, K., Kovats, S., Kroener, N., Kotlarski, S., Kriegsmann, A., Martin, E., van Meijgaard, E., Moseley, C., Pfeifer, S., Preuschmann, S., Radermacher, C., Radtke, K., Rechid, D., Rounsevell, M., Samuelsson, 
P., Somot, S., Soussana, J.-F., Teichmann, C., Valentini, R., Vautard, R., Weber, B., and Yiou, P.: EURO-CORDEX: new highresolution climate change projections for European impact research, Reg. Environ. Change, 14, 563-578, 2013.

Jones, C., Giorgi, F., and Asrar, G.: The Coordinated Regional Downscaling EXperiment CORDEX, an international downscaling link to CMIP5, CLIVAR Exchanges, 16, 34-40, 2011.

Kalognomou, E.-A., Lennard, C., Shongwe, M., Pinto, I., Favre, A., Kent, M., Hewitson, B., Dosio, A., Nikulin, G., Panitz, H.J., and Buechner, M.: A diagnostic evaluation of precipitation in CORDEX models over southern Africa, J. Climate, 26, 477-506, 2013.

Mearns, L. O., Arritt, R., Biner, S., Bukovsky, M. S., McGinnis, S., Sain, S., Caya, D., Correia Jr., J., Flory, D., Gutowski, W., Takle, E. S., Jones, R., Leung, R., Moufouma-Okia, W., McDaniel, L., Nunes, A. M. B., Qian, Y., Roads, J., Sloan, L., and Snyder, M.: The North American Regional Climate Change Assessment Program: Overview of Phase I Results, B. Am. Meteorol. Soc., 93, 1337-1362, 2012.

Prein, A., Gobiet, A., Truhetz, H., Keuler, K., Goergen, K., Teichmann, C., Maule, C. F., van Meijgaard, E., Deque, M., Nikulin, G., Vautard, R., Colette, A., Kjellstrom, E., and Jacob, D.: Precipitation in the EURO-CORDEX 0.11 degrees and 0.44 degrees simulations: high resolution, high benefits?, Clim. Dynam., 46, 383-412, 2016.

Pryor, S. C., Barthelmie, R. J., Young, D. T., Takle, E. S., Arritt, R. W., Flory, D., Gutowski Jr., W. J., Nunes, A., and Roads, J.: Wind speed trends over the contiguous United States, J. Geophys. Res., 114 D14105, doi:10.1029/2008JD011416, 2009.

Ruane, A. C., Teichmann, C., Arnell, N. W., Carter, T. R., Ebi, K. L., Frieler, K., Goodess, C. M., Hewitson, B., Horton, R., Kovats, R. S., Lotze, H. K., Mearns, L. O., Navarra, A., Ojima, D. S., Riahi, K., Rosenzweig, C., Themessl, M., and Vincent, K.: The Vulnerability, Impacts, Adaptation and Climate Services Advisory Board (VIACS AB v1.0) contribution to CMIP6, Geosci. Model Dev., 9, 3493-3515, doi:10.5194/gmd-9-3493-2016, 2016.

Rummukainen, M.: Added value in regional climate modeling, Wiley Interdisciplinary Reviews - Climate Change, 7, 145-159, 2016.
Ruti, P. M., Somot, S., Giorgi, F., Dubois, C., Flaounas, E., Obermann, A., Dell'Aquila, A., Pisacane, G., Harzallah, A., Lombardi, E., Ahrens, B., Akhtar, N., Alias, A., Arsouze, T., Aznar, R., Bastin, S., Bartholy, J., Beranger, K., Beuvier, J., BouffiesCloche, S., Brauch, J., Cabos, W., Calmanti, S., Calvet, J.-C., Carillo, A., Conte, D., Coppola, E., Djurdjevic, V., Drobinski, P., Elizalde-Arellano, A., Gaertner, M., Galan, P., Gallardo, C., Gualdi, S., Goncalves, M., Jorba, O., Jorda, G., L'Heveder, B., Lebeaupin-Brossier, C., Li, L., Liguori, G., Lionello, P., Macias, D., Nabat, P., Onol, B., Raikovic, B., Ramage, K., Sevault, F., Sannino, G., Struglia, M. V., Sanna, A., Torma, C., and Vervatis, V.: MED-CORDEX initiative for Mediterranean climate studies, B. Am. Meteorol. Soc., 97, 1187-1208, doi:10.1175/BAMS-D14-00176.1, 2016.

Solman, S. A., Sanchez, E., Samuelsson, P., da Rocha, R. P., Li, L., Marengo, J., Pessacg, N. L., Remedio, A. R. C., Chou, S. C., Berbery, H., Le Treut, H., de Castro, M., and Jacob, D.: Evaluation of an ensemble of regional climate model simulations over South America driven by the ERA-Interim reanalysis: model performance and uncertainties, Clim. Dynam., 41, 1139-1157, doi:10.1007/s00382-013-1667-2, 2013.

Takle, E. S., Gutowski, W. J., Arritt, R. W., Pan, Z., Anderson, C. J., da Silva, R. R., Caya, D., Chen, S. C., Giorgi, F. Christensen, J. H., Hong, S. Y., Juang, H. M. H., Katzfey, J., Lapenta, W. M., Laprise, R., Liston, G. E., Lopez, P., McGregor, J., Pielke, R. A., and Roads, J. O.: Project to intercompare regional climate simulations (PIRCS): Description and initial results, J. Geophys. Res., 104, 19443-19461, 1999.

Taylor, K. E., Stouffer, R. J., and Meehl, G. A.: An Overview of CMIP5 and the Experiment Design, B. Am. Meteorol. Soc., 93, 485-498, 2012.

Tebaldi, C. and Arblaster, J. M.: Pattern scaling: Its strengths and limitations, and an update on the latest model simulations, Climatic Change, 122, 459-471, 2014.

Torma, C., Giorgi, F., and Coppola, E.: Added value of regional climate modeling over areas characterized by complex terrain: Precipitation over the Alps, J. Geophys. Res., 120, 3957-3972, 2015. 